\title{
The Second International Congress of the Faculty of Dental Medicine, "Carol Davila" University of Medicine and Pharmacy Bucharest, Romania, and the 17th International Congress for Students and Young Doctors "stuDENT"
}

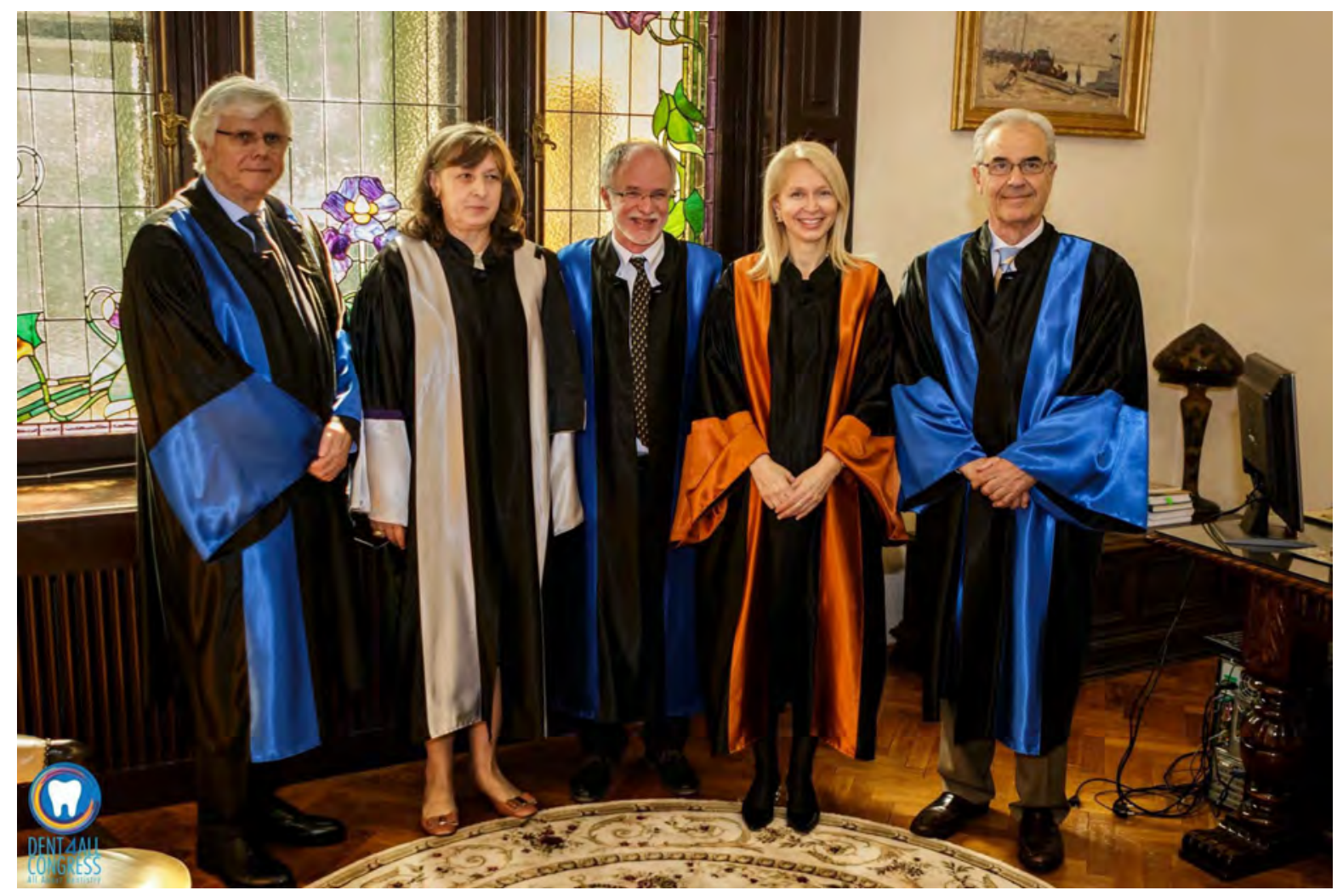

Prof. Dr. Gottfried Schmalz, Vice Rector Prof. Dr. Ecaterina Ionescu, Dean Prof. Dr. Aaron Palmon, Dean Assoc. Prof. Dr. Paula Perlea, Prof. Dr. lannis latrou

March was a month full of dental scientific events in Romania. But a core event took place in Bucharest, on March 15th-18th, at the Palace of the National Military Circle, where we had the pleasure to organize the Second International Congress of the Faculty of Dental Medicine, "Carol Davila" University of Medicine and Pharmacy, along with the 17th International Congress for Students and Young Doctors "stuDENT".

The congress was a great opportunity to relate to other professionals in the field of dentistry, to exchange knowledge, discuss and cover the major concerns that dentists face nowadays and hear about the latest information on modern dentistry. The Military Club was built in 1912 on the site of the former Sarindar Monastery (the name is inscribed on the fountain in front of the building). This neoclassic masterpiece, designed by the Romanian architect Dimitrie Maimaroiu, was built to host the social, cultural and educational events organized by the Romanian army. Nowadays, its elegant and wonderful halls are also used to host different cultural, educational and scientific events.

With a rich scientific program, the Congress was held 
in five different congress halls, where different conferences, oral communications and workshops took place. Part of the venue was reserved for the presentation of the latest products and technologies in dentistry.

The three days rich in scientific activities included eighteen sessions and 10 workshops. Out of the total18 sessions, 2 sessions - preclinical and clinical - were dedicated to the dental students and young doctors who had the chance to present their own research achievements.

As previously mentioned, the congress was intended for any dentist or even student who wanted to enhance his/her knowledge of dentistry, as all dental specialties were covered. This year, the main topic of the Congress was 'Dentistry nowadays', and subjects on all dental topics were presented: Endodontology, Periodontology, Oral and maxillofacial surgery, Orthodontics, Oral Medicine, Prosthodontics, Operative Dentistry, but also subjects related to Dentistry, such as: Neurology, Otorhinolaryngology, Anatomy and others.

More than 20 international speakers honored our invitation:

- Prof. Dr. Peter Eickholz, Goethe-Universität, Frankfurt, Germany (Periodontology - Chief of the department);

- Prof. Dr. Thomas Humel, University of Dresden, Germany (Dental Pharmacology and Toxicology);

- Prof. Dr. Michele Mignogna, University of Napoli, Italy (Oral Medicine - Chairmanof the department);

- Prof. Dr. Apostolos I. Tsolakis, University of Athens, Greece (Orthodontics);

- Prof. Dr. Anda Kfir, Goldschleger School, Tel Aviv, Israel (Endodontology - Chairman of the department);

- Prof. Dr. Igor Shugailov, Department of Stomatology, RMAPO, Moscow, Ministry of Health of the Russian Federation, Rector of the Academy for Innovative Dentistry (General Dentistry);

- Prof. Dr. Svante Twetman, University of Copenhagen, Denmark (Restorative Dentistry);

- Prof. Dr. Aaron Palmon, Dean at the Hadassah Hebrew University, Jerusalem, Israel (Oral Medicine);

- Prof. Dr. Betul Kargul, Marmara University, Istanbul, Turkey (Pediatric Dentistry - Chairman of the department);

- Prof. Dr. Gottfried Schmalz, University of Regensburg, Germany (Restorative Dentistry and Periodontology);

- Visiting Prof. Dr. Domenico Baldi, University of Genova, Italy (Prosthodontics);
- $\quad$ Prof. Dr. Giuseppe Colella, Universitaty of "Luigi Vanvitell" District, Italy (Dental Surgery - head of department);

- $\quad$ Prof. Dr. Stylianos Dalampiras, Aristotle University, Thessaloniki, Greece (OMF Surgery);

- Prof. Dr. Elisabetta Cotti, University of Cagliari, Italy (Endodontology-Chair of the department);

- Prof. Dr. Ioannis latrou, University of Athens, Greece (OMF Surgery);

- Prof. Dr. Itzhak Abramovitz, Hadassah Hebrew University, Jerusalem, Israel (Endodontology Chief of the department);

- Dr. Miriam Grushka, Toronto, Canada (Oral Medicine);

- Dr. Gabriel Tuluş, Germany (Endodontology);

- Dr. Martin Koch, University of Heidelberg, Germany (Pediatric Dentistry);

- Dr. Basel Azar, Palacký University, Prague, Czech Republic (Prosthodontics) and

- Dr. Giorgios Tsiogkas, Greece, Member of the FDI's Standing Committee of Liaison and Support.

The workshops approached interesting and useful topics: Laser in Dentistry, the Latest Generation of Composite, Dental Imagistic, Oral Surgery, Basic Life Support, Knots and Sutures, Impressions from A to $Z$, the Isolation with Rubber Dam, Implantology and Endodontics.

Last year Prof. Dr. Michael Glick and Prof. Dr. Jean François Roulet were presented with the DOCTOR HONORIS CAUSA of the "Carol Davila" University of Medicine and Pharmacy title, while this year other three important professors and scientists were honored with this prestigious title: Prof. Dr. Aaron Palmon, Prof. Dr. Gottfried Schmalz and Prof. Dr. loannis latrou.

The event could not have been made possible without the intense work and passion of the very comprehensive organizing team, with Faculty members of Faculty of Dental Medicine, and members of the Bucharest Dental Students' Association.

We were honored to cooperate with the most prestigious scientific and academic institutions that represent dentists from different specialties in matters related to the Congress organization:

- Romanian Association of Endodontics

- Romanian Society of Oral Medicine

- National Association of Pediatric Dentistry from Romania

- Romanian Society of Stomatology

Also, other doctors' and medical students' organizations supported us and were our official partners:

- National Association of Neurologists

- EDSA - European Dental Students' Association

- IADS - International Association of Dental Stu- 


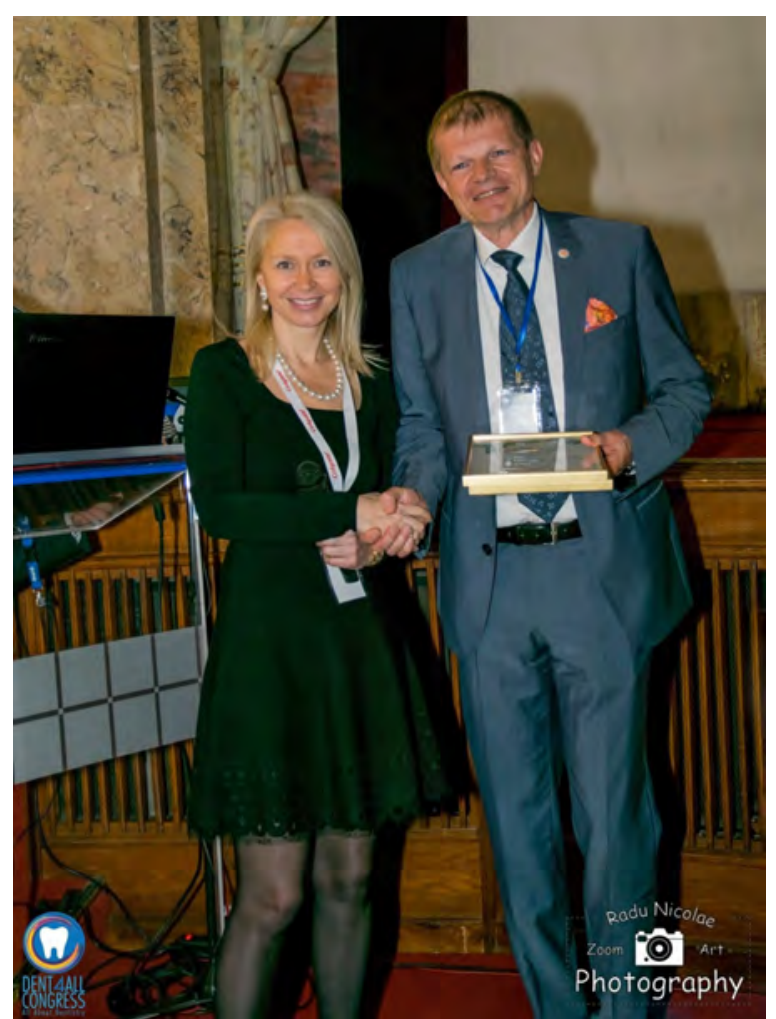

Awarding the Invited Speaker Diploma Prof. Dr. Peter Eickholz, Chief of Department of Periodontology, Faculty of Medicine, Goethe University Frankfurt / Main, Germany.

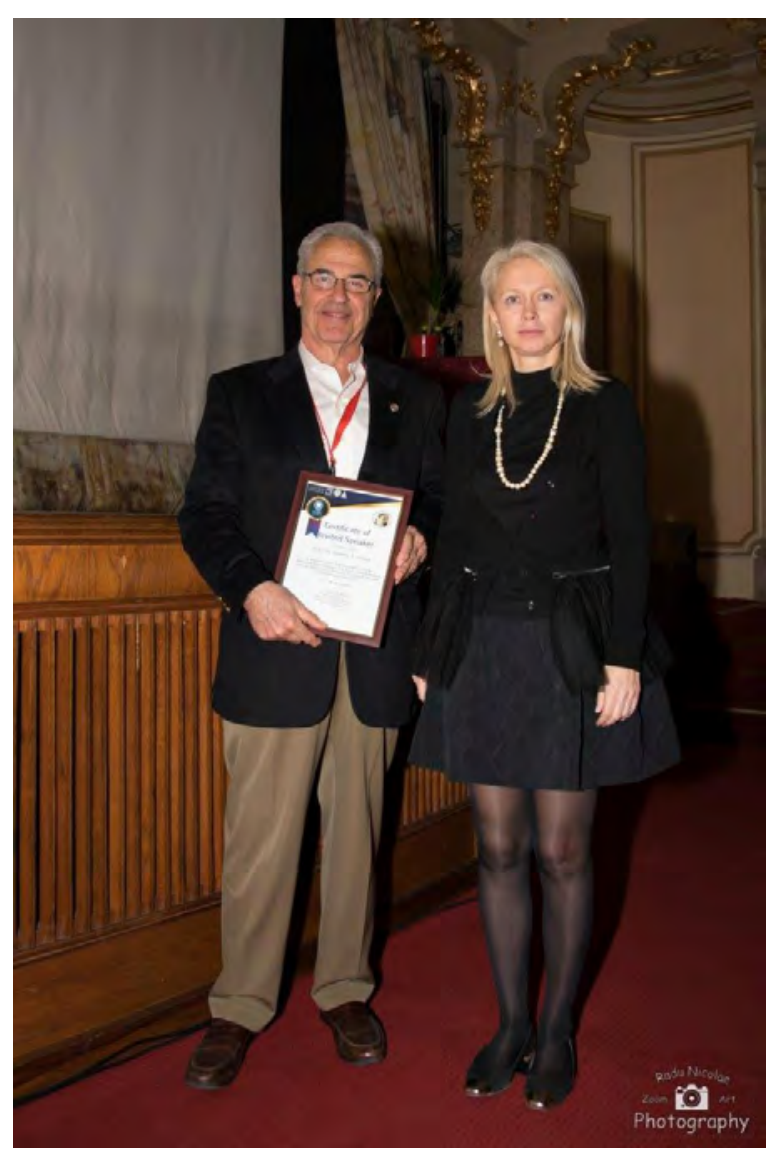

Awarding the Invited Speaker Diploma Prof. Dr. loannis latrou, Head of Department of Oral and Maxillofacial Surgery (OMFS) at the Dental School of the National and Kapodistrian University of Athens.

\section{dents}

- $\quad$ SSCR - Romanian Surgery Students' Society

- $\quad$ SSMB - Bucharest Medical Students' Society

- USR - Romanian Students' Union

The Second International Congress of the Faculty of Dental Medicine, "Carol Davila" University of Medicine and Pharmacy was a memorable scientific event, which contributed essentially towards the development of dentistry. It is a project, launched in 2017 by the Dean of the Faculty of Dental Medicine, Assoc. Prof. Dr. Paula Perlea. Each new edition of the congress is a mile stone in the scientific and practice-related field of dentistry, while helping improve knowledge in dental medicine.

Assoc. Prof. Dr. Paula Perlea

President of the Congress

Dean of the Faculty of Dental Medicine

"Carol Davila" UMPh Bucharest, Romania

Radu Gabriel Toma

President of the Dental Students Association

Bucharest, Romania

DOI: 10.25241/stomaeduj.2018.5(2).news.2 